\title{
The rise of Portuguese Antarctic research: implications for Portugal's status under the Antarctic Treaty
}

José C. Xavier ${ }^{1,2 *}$, Andrew D. Gray ${ }^{2}$ and Kevin A. Hughes ${ }^{2}$

1- Marine and Environmental Sciences Centre (MARE), Department of Life Sciences, University of Coimbra, 3004-517, Coimbra, Portugal

2 - British Antarctic Survey, Natural Environment Research Council, High Cross, Madingley Road, Cambridge, CB3 0ET, UK

* corresponding author 


\begin{abstract}
Portugal has developed an active Antarctic program over the past decade. Here, we examine Portuguese Antarctic activity using a variety of bibliometric measures, showing that Portuguese scientific output has grown substantially faster than the field as a whole, with quality remaining broadly constant. Antarctic papers made up a growing percentage of Portuguese research, up to $0.14 \%$ of papers in 2016 , a level comparable to many other nations with well-established research programs. Alongside this, Portugal has increasingly engaged in policy discussions with the production of policy papers for the Antarctic Treaty Consultative Meetings, some of which were based on Portuguese environmental science. The Antarctic Treaty reserves decision-making powers to "Consultative Parties", those who have been recognised as demonstrating substantial research activity in the continent. Our data indicates that Portugal is currently the fourth most productive non-Consultative Party, and has similar or greater output than several Parties who have already attained consultative status; its publication record is similar to that of the Czech Republic, which became a Consultative Party in 2014. The rapid growth of Portugal's Antarctic research may make it well placed to consider attaining consultative status to the Antarctic Treaty in the near future.
\end{abstract}




\section{Introduction}

Portugal has been considered an emerging Antarctic nation (Krupnik et al., 2011; Schiermeier, 2009; J. C. Xavier et al., 2013) with Portuguese researchers being regularly involved in Antarctic science through other countries' national programmes (J. C. Xavier, Vieira, \& Canário, 2006). From an initial bottom-up approach (from scientists), in the last decade, the number of Portuguese researchers are thought to have increased considerably, especially due to the impetus of the International Polar Year (IPY) in 2007-08. Engagement with the run up to the IPY led scientists, already under a framework of a Portuguese committee for the IPY (endorsed by the Foundation for Science and Technology (FCT) of the Ministry of Science, Technology and Higher Education), Portugal to define a strategy for polar science in 2006 (J. C. Xavier et al., 2006) and establish a successful scientific research programme, the Portuguese Polar Program (PROPOLAR), and educational programmes, such as LATITUTE60!, Profession Polar Scientist, and Education PROPOLAR (Kaiser, Zicus, \& Allen, 2010; J. C. Xavier et al., 2013; Zicus et al., 2011). PROPOLAR aims to promote and support the development of polar science in Portugal. It is coordinated by five Portuguese research institutes, whose activities are developed under the auspices of the Polar Office of the FCT. Key research activities are focused on marine, permafrost and cryosphere, terrestrial, atmospheric and social sciences (Portugal, 2015; J. C. Xavier et al., 2006). Furthermore, Portugal has joined several polar organizations, including the Association of Polar Early Career Scientists (APECS), the European Polar Board (EPB), Polar Educators International (PEI) and the Scientific Committee on Antarctic Research (SCAR). In 2010, Portugal signed the Antarctic Treaty and in 2014 the Protocol on Environmental Protection to the Antarctic Treaty (Madrid Protocol), under the advice and guidance of the Polar Office of the FCT and the Ministry of Foreign Affairs, and it has also been involved in major Antarctic research, education and outreach initiatives (Baeseman, Xavier, Lantuit, \& Taylor, 2011; 
Kennicutt II et al., 2015; Kennicutt II et al., 2014; May, Huffman, Xavier, \& Walton, 2014; J.

C. Xavier et al., 2013; J. C. Xavier et al., 2016; J.C. Xavier, Fugmann, Beck, Huffman, \& Jensen, 2016).

Portugal currently is a non-Consultative Party to the Antarctic Treaty (SAT, 2016); this means that Portugal may attend the annual Antarctic Treaty Consultative Meeting (ATCM) but it is not permitted to participate in governance decisions. To acquire consultative status under the Antarctic Treaty, an interested Party must demonstrate “substantial research activity" (Article IX, para. 2). Although a mechanism for considering the acceptability of a request for promotion to Consultative status has gradually emerged, scientific criteria for a unified assessment have been lacking (Dudeney \& Walton, 2012; Gray \& Hughes, 2016), with existing Parties applying their own tests which would include those of political acceptability as well as the value and extent of the scientific research. At ATCM XL in Beijing, China, the Parties agreed 'Guidelines on the procedure to be followed with respect to Consultative Party status' (Decision 2, 2017) (SAT, 2017), which provide examples of evidence likely to demonstrate a Parties suitability for consultative status.

A recent study showed that national investment on Antarctic infrastructure, such as the establishment of a research station, was not a reliable indicator of scientific output; the development of infrastructure is not necessary for scientific activity, and is closely tied to the logistical and economic capacity to do so (Gray \& Hughes, 2016). In many cases, an investment in infrastructure may be motivated by political motivations rather than purely scientific ones. (Brady, 2013; Dodds et al., 2017). Portugal has no Antarctic station, scientific vessel, or aircraft, although Portugal has contracted a dedicated flight from Punta Arenas (Chile) to King George Island (South Shetland Islands) annually since 2011 to take both Portuguese and international scientists to the Antarctic.

In order to critically evaluate the research activity of countries engaged in Antarctic 
science, Gray and Hughes (2016) described the use of two metrics, the overall number of Antarctic papers and the proportion of national scientific output on Antarctic topics ("national focus"). Here we apply these metrics to Portugal to: (1) assess the growth of the Portuguese Antarctic research activity in the last two decades (i.e. prior to IPY up to now); (2) evaluate the status of Portuguese Antarctic research activity today in relation to other Parties (Consultative and non-Consultative); and (3) provide evidence of the work carried out by Portugal that contributes to the ATCMs (e.g. number of papers presented, themes addressed, number of collaborative Parties).

\section{Methods}

The methodology followed Gray and Hughes (2016). The bibliometric searches were performed using the Scopus database (www.scopus.com), with all data retrieved on $5^{\text {th }}$ September 2017 to ensure consistency. Scopus offers a comparable coverage to Web of Science, the other general database widely used in bibliometric research. It was selected partly for consistency with the earlier study, but also because it offered slightly better coverage of non-journal material (eg book chapters) and improved coverage of smaller journals (such as Czech Polar Reports, discussed below). While the exact numbers returned by searches in either database would differ slightly, we expect the broad outline of the results would be comparable in both.

A search period beginning in 1997 was chosen because it was then that regular and continuous research started by Portuguese scientists in collaboration with other Parties (Xavier et al., 2006). Data for 2017 was omitted as only partial data was available at the time of searching. Papers were identified with variants of the Scopus search query given below, returning a total of 44177 papers for the twenty years 1997-2016 inclusive: 
(TITLE-ABS-KEY (antarct* OR "southern ocean" OR "ross sea" OR "amundsen sea" OR "weddell sea") AND NOT TITLE-ABS-KEY(candida OR "except antarctica" OR "not antarctica")) AND (LIMIT-TO(PUBYEAR, 1997))

To identify Portuguese papers specifically, an additional filter was added ... AND (LIMIT-TO(AFFILCOUNTRY, "Portugal"))

This produced a total of 210 "Portuguese" Antarctic papers. It should be noted that Scopus country identification is based on the location of the author's listed affiliation, and so will identify authors of any nationality publishing while based at a Portuguese institution, but will not identify "Portuguese" authors based overseas. No attempt was made to weight scientific publication output by number of contributors from a given country, lead authorship, dual affiliations or other factors. Some caution should also be taken for the early years, as a small proportion of papers in Scopus do not have the country correctly indexed (or indexed at all), and while we assume any errors are randomly distributed across the publications, it may have a disproportionate effect on those years with a small number of Portuguese papers.

The results were adjusted to include a manual count of Antarctic-focused papers from Czech Polar Reports; this journal is only indexed in Scopus from 2014 onwards, but includes a significant number of Czech papers published before this date, and a smaller number from other countries. As the Czech Republic is the most recent country to attain consultative status, this data is of particular interest here, and so it was felt appropriate to adjust the total number of papers accordingly. However, the citation measures were calculated purely on papers indexed in Scopus; comparable data for citations of the added papers was not 
available, and it was felt the small numbers involved would be unlikely to skew the totals.

\section{Results}

Growth of Antarctic Research Activity of Portugal 1997-2016

There has been a steady growth in Portuguese Antarctic scientific research outputs throughout the study period, rising from one or two papers per year in the late 1990s to 34 papers per year in 2016, a dramatic increase (Figure 1). This is a much higher rate than the growth in the field overall, which has approximately doubled from just over 1500 papers to just under 3000 . Portugal was ranked $39^{\text {th }}$ among countries by the number of Antarctic papers produced in $1997-2001$, and rose to $28^{\text {th }}$ in $2012-2016$, when it was producing slightly under $1 \%$ of all Antarctic research papers.

Citation rates of Portuguese papers were quite variable due to the small number of papers involved (Figure 1); the one paper published in 1999 had more than six times the citations of the one paper published in 2000 , for example. However, once the annual number of papers published increased in the late 2000s, we can see a general trend whereby Portuguese papers mostly get slightly more citations than other Antarctic papers published that year, suggesting that they are of comparable or of slightly higher quality.

The relative significance of Antarctic research within Portugal has also increased. Antarctic papers made up only $0.03 \%$ of the country's published papers during the period 1997-2001, rising steadily to around $0.14 \%$ in 2016, indicating a growing national focus on Antarctic research (Figure 1).

Antarctic Research activity of Portugal in relation to other Consultative and nonConsultative Parties (2012-16)

In recent years, Portugal's output has been predominantly in the middle of the range 
of Treaty nations (Fig 2a). Over the 2012-16 period, Portugal ranked $28^{\text {th }}$ among the 53 Treaty Parties (i.e. 29 Consultative and 24 non-Consultative) in terms of total papers published. This made them the fourth most productive of the non-Consultative parties, behind Canada, Switzerland, and Denmark, and substantially more productive than five of the 29 Consultative Parties.

In terms of 'national focus' (Fig 2a, 2b), Portugal was $33^{\text {rd }}$ of the 53 Treaty Parties, with $0.121 \%$ of its scientific papers over the five years being on Antarctic topics. This is a higher level of national focus than six of the existing Consultative Parties, many of whom have long-established and well-developed Antarctic programmes. Portuguese papers from this period were cited an average of 8.9 times (Fig 2b), placing them $32^{\text {nd }}$ among the 53 Treaty Parties, and ahead of many Consultative Parties with larger scientific output. The average citation rate for all Antarctic papers was 8.5 cites per paper, suggesting that Portuguese papers are around or slightly above average in quality as measured by this metric. However, it should be noted that Portuguese output continually increased over this period - a 70\% increase in Portuguese Antarctic papers published between 2012 and 2016, as opposed to an overall increase of just $4 \%$ in total Antarctic papers - and an average citation-based measure is thus going to be skewed by a large number of newer papers, which have had less time to attract citations. The year by year data (Fig 1c) suggested that if weighted by year, Portugal would likely score more highly using this metric.

Bibliometric profile of Portuguese Antarctic research, 2012-16

The majority of Portuguese papers are co-authored with researchers from other countries, a pattern common in modern Antarctic research (Dastidar 2007). Only 13 of 136 papers between 2012 and 2016 were solely authored by Portuguese researchers, with large numbers co-authored with researchers from the United Kingdom (45), Spain (41), the United 
States (36), Brazil (23) and Germany (22).

Published research was dominated by researchers from universities rather than independent research institutes; only five of the papers did not appear to have an author based at a Portuguese university. The largest group of papers, $40 \%$ of the total, was from researchers at the Universidade de Lisboa (55), with other groups at the Universidade de Coimbra (28), Universidade de Aveiro (21), Universidade de Porto (17), and smaller numbers of papers from the Universidade de Algarve, Universidade Nova de Lisboa, Universidade de Évora, and the Universidade dos Açores. These data suggested that while there was a strong concentration of research output at a leading institution, there was a general distribution of interest in Antarctic topics around the country with eight of the twelve public universities in the country represented here.

Authorship was more widely distributed than affiliation; there were two Portuguese researchers with 21 and 17 papers respectively, and another six who were co-authors on five papers or more. However, more than $60 \%$ of papers (84) did not have any of these eight researchers among their authors, suggesting that there was a small group of highly active Antarctic researchers and a much larger number of scientists who have worked on Antarctic topics alongside other fields of interest. The research topics covered by the papers include those key research activities for the IPY (J. C. Xavier et al., 2006), out of which some papers are starting to be the basis for ATCM papers (see below).

\section{Contribution of papers of Portugal to ATCMs}

Portugal signed the Antarctic Treaty in 2010, with official presence at ATCMs since 2013. Since then, a total of 15 policy papers have been submitted to the ATCM (Figure 3). These papers were mostly submitted with other Parties (12) with only a minority submitted by Portugal alone (3). Portugal submitted papers with 11 other Parties, particularly the United 
Kingdom (11), Belgium, Brazil, Bulgaria (8) and Chile (7) (Table 1), as a joint submission with a Consultative Party is required if the paper is designated a Working Paper as NonConsultative Parties (e.g. Portugal) are only able to submit Information and Background Papers in their own right. The number of papers submitted by Portugal has increased gradually, up to a current level of c. 4-5 papers per year (Figure 3).

\section{Discussion}

Growth of Antarctic research activity of Portugal 1997-2016

There has been a considerable growth of Antarctic research activity by Portugal in the last two decades, from fewer than five papers per year (from 1997 to 2004) to 34 papers per year in 2016 (Figure 1). Such growth can be attributed to various factors. The IPY 2007-2008 provided an excellent opportunity to form a Portuguese committee for the International Polar Year. This brought the Portuguese polar scientific community together to take the opportunity to establish new international collaborations, while reinforcing those collaborations already ongoing. Moreover, it brought the Portuguese polar scientific community in contact with the national funding body (Foundation for Science and Technology, Ministry of Science and Higher Education of Portugal) to support polar research, which had almost no target polar funding available before the IPY (Schiermeier, 2009). As a legacy of the IPY work, the Portuguese Polar Programme PROPOLAR was developed and established (J. C. Xavier et al., 2013), while engaging with established polar organizations such as SCAR and CONMAP (see Introduction). Also, an educational polar programme, named LATITUDE60!, support by the national agency Ciência Viva, provided vital education and outreach activities within Portugal to link the scientific community with schools and the general public (Kaiser et al., 2010). Finally, having support for early career scientists, through research grants from a private bank, facilitated the new generation of early 
career scientists to carry out polar research and develop their careers. Financial support for polar research groups, opportunities for early career scientists, and projects with strong educational links, all provided a solid basis for the growth of research outputs and Portuguese engagement with Antarctic research activities.

Status of Antarctic research activity of Portugal today in relation to other Parties (Consultative and non-Consultative)

Portugal has been one of the most scientifically productive of the non-Consultative Parties to the Antarctic Treaty during the period 2010-15, and produced more research papers than even some Consultative Parties. The data suggest that Portugal's rate of output is steadily increasing and that, if current trends are continued, it is likely to be in an even stronger position in terms of scientific output and activity in future years. This is supported by the Portuguese Polar Program PROPOLAR that has been in existence for fewer than 10 years, and therefore it still within a phase of consolidation.

In 2014 the Czech Republic became the most recent nation to gain consultative status, and thus provides a useful benchmark as a nation whose scientific activity was considered adequate for the acquisition of consultative status by the other Consultative Parties. Portuguese scientific output is broadly comparable to that of the Czech Republic. In 2015 and 2016 Portugal produced 33-34 papers/year; if this output was continued over a five-year period, it would be closely comparable to the five-year output of the Czech Republic (averaging 34.2 papers/year in 2012-16). The recent 'national focus' level of Portugal on Antarctic research $(0.14 \%$ in $2015-16)$ is close to the average level of the Czech Republic (0.155\% in 2012-16), and ahead of almost all other non-Consultative Parties. Indeed, the citation levels of Portuguese papers are comparable or slightly above the overall average in Antarctic research, substantially ahead of the level attained by the Czech Republic, and are 
generally more highly cited than those from a large number of Consultative Parties. Both Portugal and Czech republic also recently became members of the Arctic Science Committee (IASC), in 2015 and 2012, respectively, and Portugal's Arctic research also substantially increased in the last few years, also demonstrating an engagement of these two Parties in Arctic research.

Work carried out by Portugal at the ATCMs

The engagement of Portugal at the ATCMs has developed rapidly, as reflected by the number of papers submitted, the number of nations involved in the papers produced and the subjects addressed (Figure 3) (see Dudeney and Walton (2012) for an earlier more comprehensive analysis). Moreover, Portugal has co-led on issues with other nations, such as Antarctic education and outreach (Table 1), engaged in major international initiatives, such as the SCAR Horizon Scan and EU-POLARNET (Table 1) and, more recently, contributed to discussions relating to environmental conservation, such as trace element contamination (Table 1). In the future Portugal will continue to work within the Antarctic Treaty System to actively contribute to the environmental protection of the Antarctic and engage with the Committee for Environmental Protection (CEP), SCAR and other Parties, while simultaneously engaging (and informing) the Portuguese Antarctic scientific community on how their research can have policy implications (Hughes, Liggett, Roldan, Wilmotte, \& Xavier, 2016). Indeed, Portuguese Antarctic scientific output is comparable in both volume and "national focus" to the Czech Republic, who successfully attained Consultative status in 2014. Both factors are also increasing over time. In terms of quality, measured by citations, it is slightly above average for the field as a whole. While these are purely overall bibliometric measurements, they do point towards a substantial interest and investment in polar science, generally consistent with that of the smaller Consultative Parties. 
Put together, these factors suggest that should Portugal wish to put itself forward for consultative status in the future, it has already gone a substantial way to meeting the guidelines set out by the ATCM in 2017 (Annex, Decision 2, 2017) (SAT, 2017). For an application for Consulative status, it is required evidence of future strategic plans of Portugal for the Antarctic region, which are now being developed under an strategic national agenda coordinated by FCT. It should be noted that Portugal does not operate any dedicated Antarctic research facilities or support infrastructure, but the ATCM has emphasised that doing so is not a formal requirement for consultative status. Indeed, one highly productive Consultative Party, the Netherlands, operated successfully on a purely collaborative basis for many years.

\section{Acknowledgements}

We thank the Foundation for Science at Tecnhology (FCT) and the Ministry of Foreign Affairs of Portugal, through their work in the national delegation to the Antarctic Treaty since 2013. This work is an international effort under the Scientific Committee on Antarctic Research (SCAR) associated programmes, expert and action groups, namely SCAR AnT-ERA, SCAR Ant-ECO and ICED. JX was supported by the Investigator FCT program (IF/00616/2013) and this study benefited from the strategic program of MARE, financed by FCT (MARE- UID/MAR/04292/2013). The work contributes to the British Antarctic Survey (BAS) Environment Office Long Term Monitoring and Survey project (EO-LTMS) and AG and $\mathrm{KH}$ are supported by Natural Environment Research Council core funding to BAS.

\section{References}

Baeseman, J., Xavier, J. C., Lantuit, H., \& Taylor, A. (2011). Early Career Researcher Activities during the 4th International Polar Year. In I. Krupnik, I. Allison, R. Bell, P. Culer, D. Hik, J. Lopez-Martinez, V. Rachold, E. Sarukhanian, \& C. Summerhayes (Eds.), 
Understanding Earth Polar Challenges: International Polar Year 2007-2008 (pp. 511522): University of the Arctic, Rovaniemi, Finland/CCI Press.

Brady, A-M. (2013). The emerging politics of Antarctica. Routledge, London, UK.

Dodds, K., Hemmings, A.D., \& Roberts, P. (2017). Handbook on the politics of Antarctica. Edward Elgar Publishing, Cheltenham, UK.

Dudeney, J. R., \& Walton, D. W. H. (2012). Leadership in politics and science within the Antarctic Treaty. Polar Research, 31, 1-9.

Gray, A. D., \& Hughes, K. A. (2016). Demonstration of "substantial research activity" to acquire consultative status under the Antarctic Treaty. Polar Research, 35, 34061.

Hughes, K. A., Liggett, D., Roldan, G., Wilmotte, A., \& Xavier, J. C. (2016). Narrowing the science/policy gap for environmental management. Antarctic Science, 28, 325. doi:http://dx.doi.org/10.1017/S0954102016000407

Kaiser, B., Zicus, S., \& Allen, B. (2010). Polar Science and Global Climate: An International Resource for Education \& Outreach: Pearson Custom Publishing, Essex, UK

Kennicutt II, M. C., Chown, S. L., Cassano, J., Liggett, D., Peck, L. S., Massom, R., . . . Sutherland, W. J. (2015). Future directions in Antarctic and Southern Ocean science: 1st SCAR Horizon Scan. Antarctic Science, 27, 3-18.

Kennicutt II, M. C., Chown, S. L., Cassano, J. J., Liggett, D., Massom, R., Peck, L. S., . . Yang, H. (2014). Six priorities for Antarctic Science (and supplementary material). Nature, 512, 23-25. doi:10.1038/512023a

Krupnik, I., Allison, I., Bell, R., Cutler, P., Hik, D., López-Martinez, J., . . Summerhayes, C. (2011). Understanding earth's polar challenges : International Polar Year 2007-2008 (Vol. no. 1): University of the Arctic, Rovaniemi, Finland/CCI Press

May, I., Huffman, L. T., Xavier, J. C., \& Walton, D. W. H. (2014). Education and Polar Research: Bringing Polar Science into the Classroom. Journal of geological resource and engineering, 4, 217-221.

Portugal. (2015). Portugal's Antarctic Science and Policy Activities: a Review. ATCMXXXVIII IP3, 1-10 June 2015, Sofia, Bulgaria.

SAT. (2016). Final report of the thirty-ninth Antarctic Treaty consultative meeting. Santiago de Chile. 23 May-1 June 2016. Accessed on the internet at http://www.ats.aq/devAS/info finalrep.aspx?lang=e\&menu=2 on 21 April 2017.

SAT. (2017). Final report of the fortieth Antarctic Treaty consultative meeting. Beijing. $2 \mathrm{~s}$ May-1 June 2017. Accessed on the internet

at http://www.ats.aq/devAS/info finalrep.aspx?lang=e\&menu=2 on 23 October 2017.

Schiermeier, Q. (2009). In from the cold. Nature, 457, 1072-1077.

Xavier, J. C., Barbosa, A., Agusti, S., Alonso-Sáez, L., Alvito, P., Ameneiro, J., . . . B., V. (2013). Polar marine biology science in Portugal and Spain: Recent advances and future perspectives. Journal of Sea Research, 83, 9-29. doi:(10.1016/j.seares.2013.05.013)

Xavier, J. C., Brandt , A., Ropert-Coudert, Y., Badhe, R., Gutt, J., Havermans, C., . . . Sutherland, W. J. (2016). Future challenges in Southern Ocean ecology research. Front. Mar. Sci., 3(94). doi:10.3389/fmars.2016.00094

Xavier, J. C., Fugmann, G., Beck, I., Huffman, L., \& Jensen, E. (2016). Education on Biodiversity in the Polar Regions. In P. Castro, U. M. Azeiteiro, P. Bacelar-Nicolau, W. L. Filho, \& A. M. Azul (Eds.), Biodiversity and education for sustainable development (pp. 43-56): Springer International Publishing, Switzerland.

Xavier, J. C., Vieira, G. T., \& Canário, A. (2006). Portuguese Science Strategy for the International Polar Year: Centre of Marine Sciences, University of Algarve, 42pp. 
Zicus, S., Almeida, M., Edwards, K., Hik, D., Huffman, L., Kaiser, B., . . Xavier, J. C. (2011). IPY Education Activities. In I. Krupnik, I. Allison, R. Bell, P. Cutler, D. Hik, J. LópezMartinez, V. Rachold, E. Sarukhanian, \& C. Summerhayes (Eds.), Understanding Earth's polar challenges: International Polar Year 2007-2008 (Vol. 1, pp. 481-496): University of the Arctic, Rovaniemi, Finland/CCI Press 

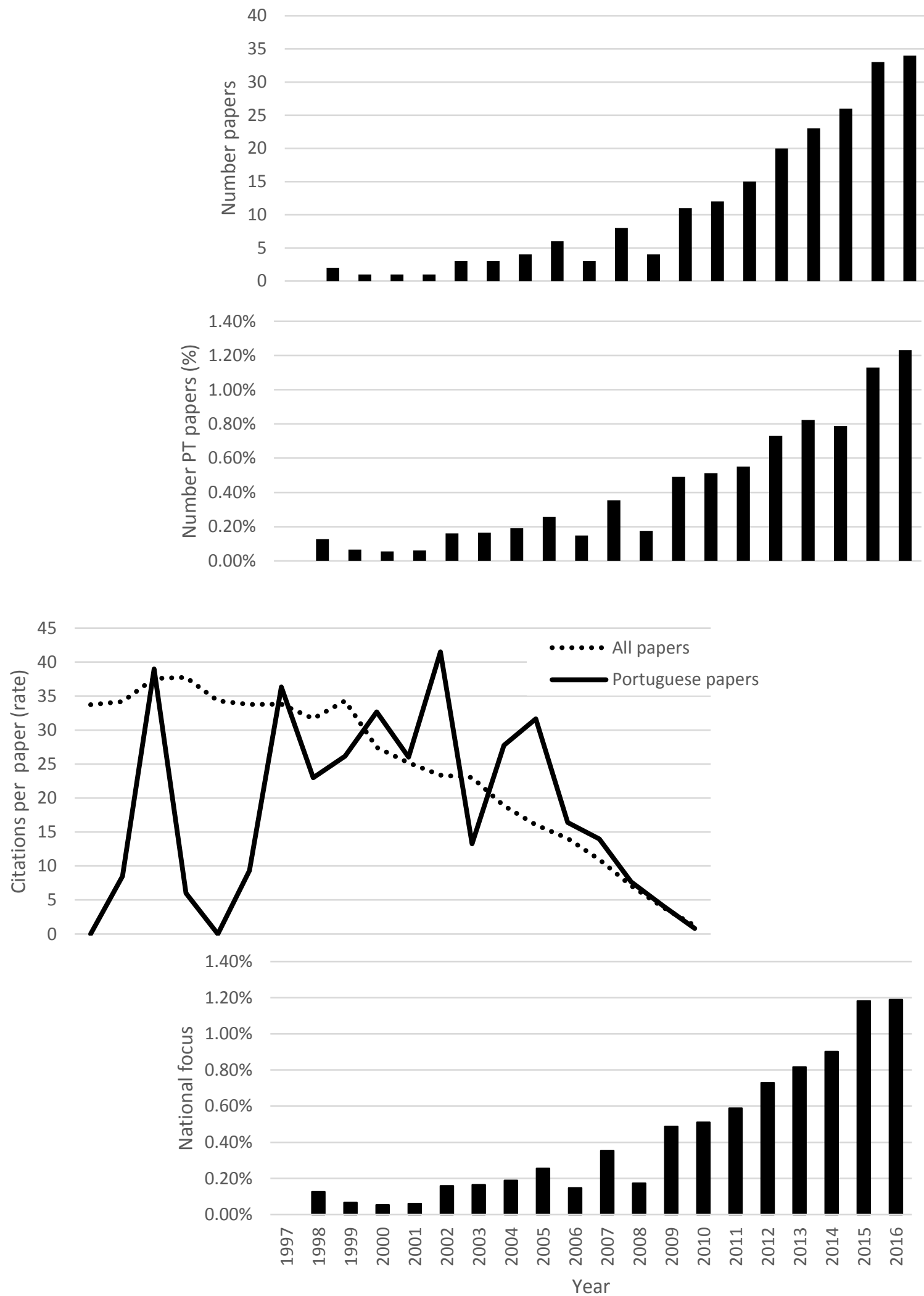

Figure 1. Metrics assessing Antarctic research activity of Portugal based on scientific research publications generated during the study period of 1997-2016. Caution should be paid 
for the earliest data (see methods). Visualize panels from top to bottom: a) number of papers of Portugal, b) number of papers produced in relation to all papers published by all Antarctic scientific community, c) mean citations per paper and d) national focus.

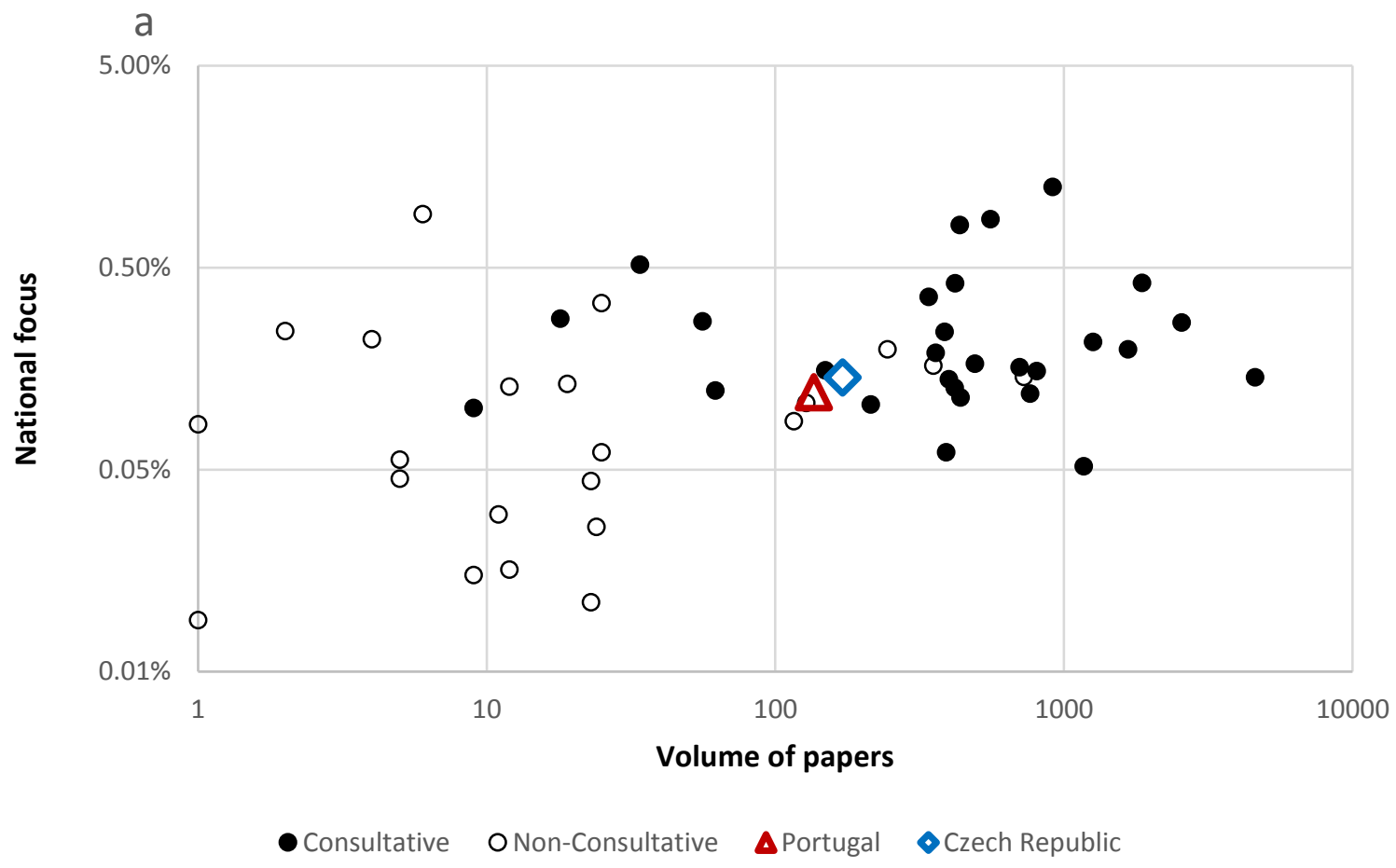

b

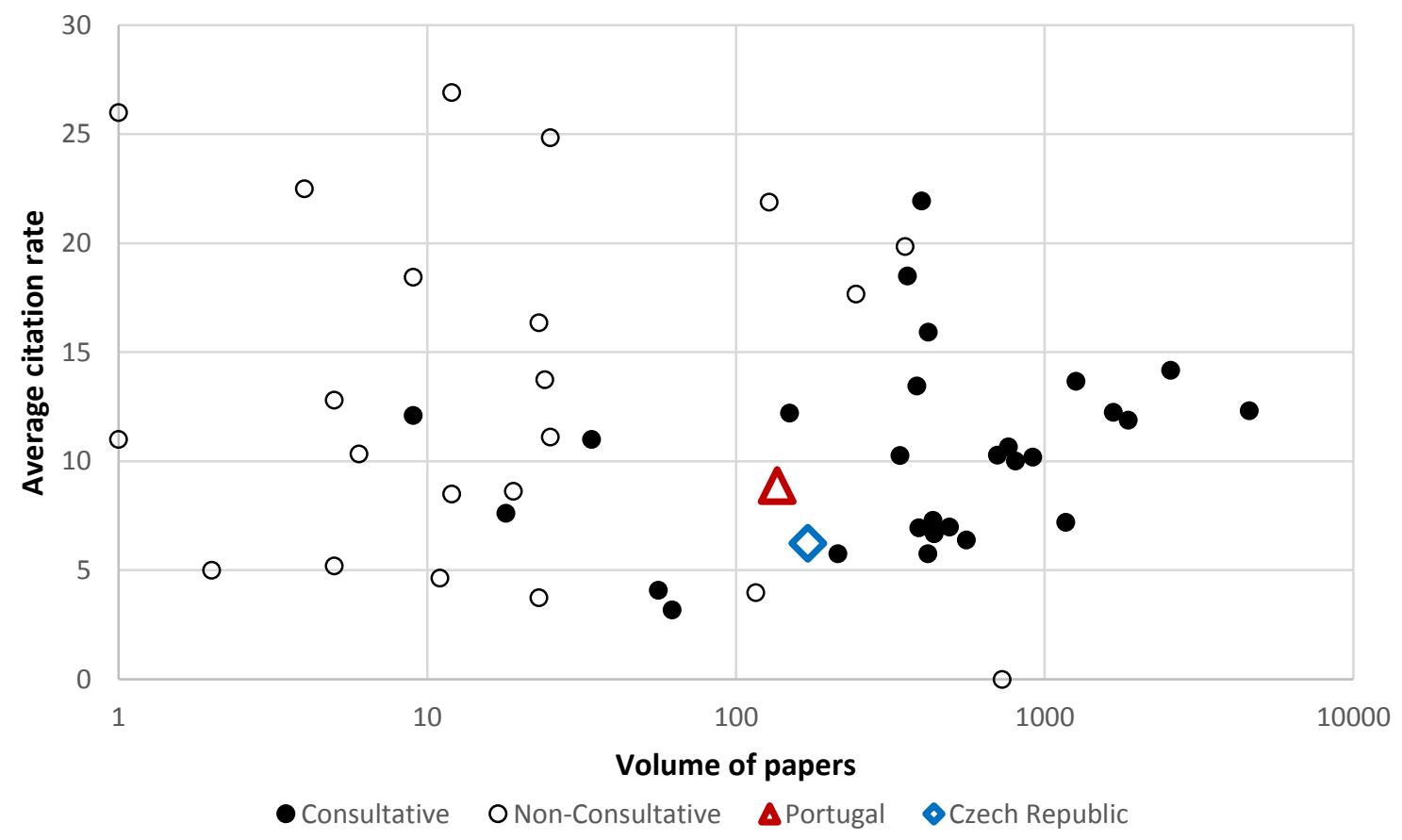

Figure 2. Metrics comparing Portugal to other Antarctic Treaty nations over the 2012-16 period in terms of a) national focus against overall volume of Antarctic papers from that country; and b) average citation rate against overall volume of Antarctic papers from that 
country. Consultative and non-consultative parties are marked separately, and both Portugal and the Czech Republic (the most recent Consultative Party) are highlighted.

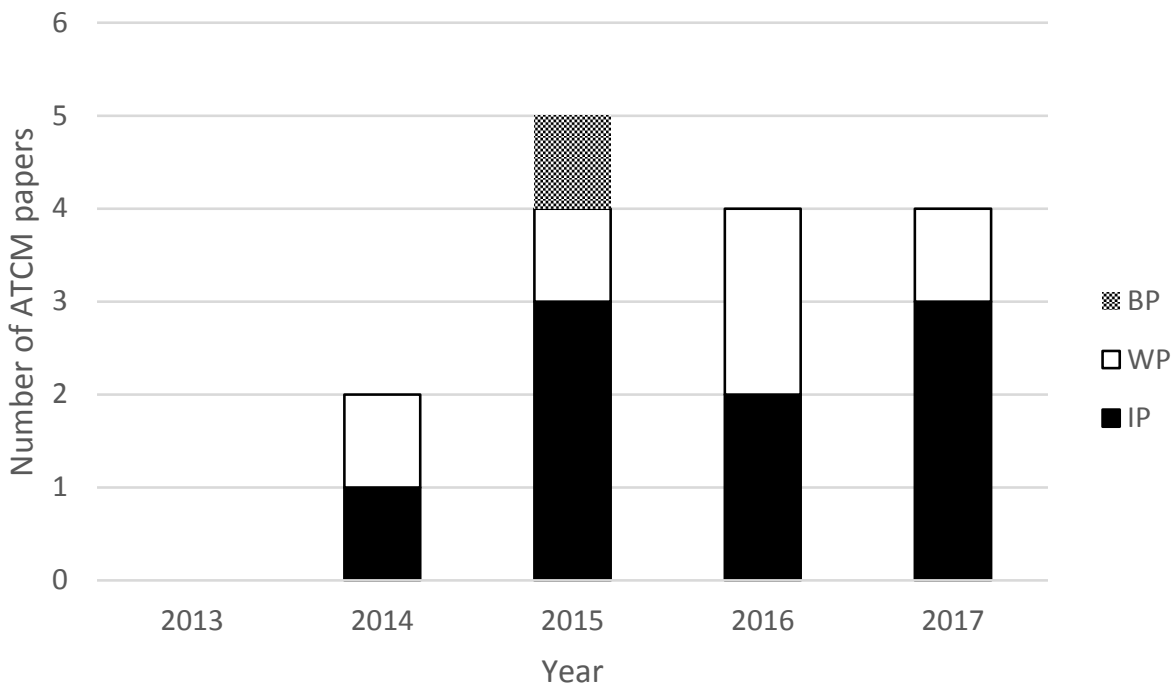

Figure 3. Number of papers submitted by Portugal at Antarctic Treaty Consultative Meetings (ATCM's) (IP = Information Papers; WP = Working papers; $\mathrm{BP}=$ Background papers). 
Table 1. The working (WP), information (IP) and background papers (BP) submitted to Antarctic Treaty Consultative Meetings (ATCM's, including within the sessions of the Committee of Environmental Protection (CEP)) by Portugal up to 2017 (Parties: BEL = Belgium, BRA = Brazil, BUL $=$ Bulgaria, $\mathrm{CHL}=$ Chile, $\mathrm{ESP}=$ Spain, ITA $=$ Italy, FRA $=$ France, $\mathrm{NHL}=$ Netherlands, $\mathrm{PRT}=\mathrm{Portugal}, \mathrm{RUS}=\mathrm{Russian}$ Federation, SCAR = Scientific Committee on Antarctic Research, USA = United States of America).

\begin{tabular}{|c|c|c|c|c|}
\hline Year & Type & Title & $\begin{array}{l}\text { ATCM/CEP } \\
\text { Session }\end{array}$ & Sponsors \\
\hline 2014 & IP 2 & $\begin{array}{l}\text { The mission and objectives of the recently established Polar Educators } \\
\text { International (PEI) }\end{array}$ & ATCM 15 & PRT, BRA, BEL, BUL \\
\hline 2014 & WP 9 & $\begin{array}{l}\text { Education and Outreach activities associated with Antarctic Treaty Consultative } \\
\text { Meetings (ATCM) }\end{array}$ & ATCM 15, CEP 13 & BRA, BEL, BUL, PRT, GBR \\
\hline 2015 & IP 2 & Portugal's Antarctic Education and Outreach Activities & ATCM15 & PRT \\
\hline 2015 & IP 3 & Portugal's Antarctic Science and Policy Activities: a Review & ATCM 13 & PRT \\
\hline 2015 & IP 63 & EU-PolarNet - Connecting Science with Society & ATCM 13 & GER, BEL, BUL, FRA, PRT \\
\hline 2015 & WP 52 & Co-chairs' report of the Workshop on Education, Sofia, Bulgaria, May 2015 & ATCM 15 & BUL, BEL, BRA, CHL, PRT, GBR \\
\hline 2015 & BP 26 & Report on the ATCM XXXVIII Workshop on Education and Outreach & ATCM 15 & BUL, BEL, BRA, CHL, PRT, GBR \\
\hline 2016 & IP 7 & $\begin{array}{l}\text { POLAR WEEKS: an Education and Outreach activity to promote Antarctic } \\
\text { science and the Antarctic Treaty System }\end{array}$ & ATCM 11, CEP 13 & PRT, BRA, BUL, FRA, GBR \\
\hline 2016 & IP 8 & Assessment of trace element contamination within the Antarctic Treaty area & ATCM 15, CEP 11 & PRT, CHL, GER, RUS, GBR \\
\hline 2016 & WP 20 & Enhancing Antarctic Education and Outreach Visibility & ATCM 11 & $\begin{array}{l}\text { ESP, GBR, PRT, BEL, BUL, CHL, } \\
\text { ITA }\end{array}$ \\
\hline 2016 & WP 24 & First report of the Intersessional Contact Group on Education and Outreach & ATCM 11 & BUL, CHL, BEL, BRA, GBR, PRT \\
\hline 2017 & WP 24 & Second report of the Intersessional Contact Group on Education and Outreach & ATCM 11 & $\begin{array}{l}\text { BUL, BEL, BRA, CHL, PRT, ESP, } \\
\text { GBR }\end{array}$ \\
\hline 2017 & IP 22 & Trace element contamination and availability within the Antarctic Treaty Area & CEP 11 & PRT, CHL, GER, RUS, GBR \\
\hline 2017 & IP 23 & $\begin{array}{l}\text { Historical and geo-ecological values of Elephant Point, Livingston Island, South } \\
\text { Shetland Islands }\end{array}$ & CEP 9e & PRT, BRA, ESP, GBR \\
\hline 2017 & IP 24 & $\begin{array}{l}\text { Future Challenges in Southern Ocean Ecology Research: another outcome of the } \\
1 \text { st SCAR Horizon Scan }\end{array}$ & ATCM 15, CEP 13 & $\begin{array}{l}\text { PRT, BEL, BRA, FRA, GER, } \\
\text { NHL, SCAR, GBR, USA }\end{array}$ \\
\hline
\end{tabular}

